\title{
Student Perceptions of Feedback in Higher Education
}

\author{
Jonathan Glazzard \\ Leeds Beckett University \\ Leeds, England \\ Samuel Stones \\ Leeds Beckett University \\ Leeds, England
}

\begin{abstract}
Text Feedback is critical to students' academic development in higher education. Despite this, evidence suggests that students do not consistently engage with feedback or recognise the value of it. This study explored student perceptions of feedback in one university in England. Data were collected using focus groups. The results indicated that the participants valued feedback that is detailed and personal. They also demonstrated a preference for verbal feedback rather than written feedback. Participants recognised the benefits and limitations of peer feedback and there was evidence to suggest that participants valued the judgements of their lecturers above those of their peers. The data indicate that lecturers should utilise a range of feedback modes, including face-to-face, verbal, written, audio and video feedback. The study suggests that the use of written feedback in higher education may not be effective because students may not engage effectively with it, particularly if they achieve a high grade. Taking into consideration the important role that feedback plays in promoting learning, it is vital that modes of feedback are used which students are likely to engage with. Given the fact that students have different preferences, it is therefore suggested that lecturers utilise a variety of modes of feedback. The limitation of this study was the small sample size and therefore the results are not generalisable.
\end{abstract}

Keywords: feedback; assessment; higher education; university; grading.

\section{Introduction}

This study explored students' perspectives of feedback in higher education. It also identifies implications for effective feedback practices within this sector. In England the outcomes from the National Student Survey (NSS) consistently demonstrate negative student perceptions of their feedback at undergraduate level (Boud \& Molloy, 2012; Nicol, Thomson \& Breslin, 2014). Yet despite this, 
feedback is considered an essential part of the learning process in higher education. Institutions in the UK have responded by making efforts to enhance the quality of feedback that is provided by lecturers by focusing on increasing the level of detail and improving the clarity, structure, promptness and relevance of the feedback that they provide to students. However, there is little evidence to suggest that these enhancements have improved student satisfaction ratings in UK surveys (Nicol, Thomson \& Breslin, 2014).

\section{Key literature}

The literature explores the characteristics of effective feedback and students' perspectives on specific modes of feedback. These themes relate to the research questions which are identified later in this paper.

Research demonstrates that feedback plays a critical role in enhancing student learning (Ramsden, 2003). Effective feedback is timely and appropriate (Ramsden, 2003) and personalised to the student (Knight \& Yorke, 2003). Timely and constructive feedback enhances student learning (Gibbs \& Simpson, 2004), provided that students engage with it by addressing the identified targets to support their academic development and performance in future assessments (Boud, 2007). Feedback which does not identify generic aspects for students' academic development or feedback which is delivered too late is often perceived by students as being less useful and is rarely actioned in subsequent assessments (Bevan, Badge \& Cann, 2008; Weaver, 2006).

The challenge for academics, it seems, is to get students to engage with feedback because this is critical to successful student learning and achievement (Price, Handley \& Millar, 2010). Regardless, research suggests that students do not always use their feedback to improve their future work (King, McGugan \& Bunyan, 2008). However, it cannot be assumed that students know how to engage with, and learn from, feedback (Thompson \& Lee, 2012). Research suggests that students are more likely to learn from feedback if they analyse it, reflect on it, ask questions about it and make connections with prior feedback (Price, Handley \& Millar, 2011).

Students should understand the assessment rationale and criteria to successfully engage with feedback (Duncan, 2007). Hounsell (1997) stated that the feedback provided by lecturers often does not lead to improvements as students find that it does not connect to the assessment criteria. Research also suggests that when students do not understand the assessment criteria, they are less likely to produce good quality work (MacLellan, 2001). Therefore, to address this issue Nicol (2010) proposes strategies. Examples include analysing assessments completed by previous cohorts of students, identifying how well the assessment criteria have been addressed and pinpointing the strengths and weaknesses of the work. To help students succeed in future assessments lecturers should provide feedback to address future development by including feed forward (Garrison \& Anderson, 2003; Price, Handley \& Millar, 2010). Feed forward can include looking at draft versions of students' work, thus providing students 
with opportunities to learn from formative feedback prior to submitting a summative assessment (Wheatley, McInch, Fleming \& Lord, 2015).

Feedback is usually provided in a written format, which students find useful, especially when it is word processed and easy to read (Hepplestone \& Chikwa, 2014). One way of actively engaging students in written feedback is through peer review (Cartney, 2010). Peer review provides opportunities for students to evaluate and make judgements about their peers' work using either a written or verbal commentary (Nicol, Thomson \& Breslin, 2014). Research on peer feedback is largely positive, with students identifying peer feedback as more comprehensible and helpful than lecturer feedback (Falchikov, 2005). Peer feedback generally takes a non-directive approach in which students make comments relating to the general strengths and weaknesses of the work of their peers (Nicol, Thomson \& Breslin, 2014). Students have also stated that the process of evaluating their peers' work triggers a reflective process for themselves, allowing them to use the feedback they have generated for others to update their own thinking and assessments (Nicol, Thomson \& Breslin, 2014). This supports Cowan (2010) who has argued that the ability to make judgements of the work of others and produce a written evaluation of that work is a key skill that underpins critical thinking and reflective capabilities. It is also a key professional skill in the workplace.

Although most feedback is provided in a written format, feedback can take a variety of forms including dialogic, audio and video modes. Nicol (2010) has expressed concerns about the marginalisation of dialogic feedback in higher education, with written feedback being more common. Despite being timeconsuming, dialogic feedback can facilitate negotiation, clarify confusions and create discussion (Yang \& Carless, 2013). Feedback dialogues have been described as collaborative discussions between lecturers and students or between students in relation to a piece of feedback, which facilitate a shared understanding of the feedback and the points for subsequent academic development (Blair \& McGinty, 2013). Research has consistently emphasised the importance of dialogic feedback to improve student learning (Black \& Wiliam, 1998). Blair \& McGinty (2013) found that students valued being able to discuss feedback in one-to-one tutorials with a lecturer. These opportunities enable students to ask questions, clarify their understanding and seek clarification. In these instances, it is important for lecturers to communicate clearly with students by explaining any content or assessment-related terminology (Clark \& Rimmershaw, 2000). Blair and McGinty (2013) introduced the concept of 'feedback negotiation', a two-way discussion between a lecturer and a student, which reduces the power imbalances that are usually evident. Although students are often happy for lecturers for be in control of feedback (Blair \& McGinty, 2013), it is important for students to take greater ownership of their feedback during these discussions. Social constructivist approaches to assessment are not new (Barr \& Tagg, 1995). However, only recently are they beginning to have an effect on feedback practices and there is still a gap in the literature in relation to students' perspectives on dialogic feedback (Blair \& McGinty, 2013). 
There is a growing interest in the use of audio feedback in higher education (Morris \& Chikwa, 2016). The use of technology creates an innovative opportunity to provide students with different modes of feedback (Evans, 2013). Merry and Orsmond (2008) reported that students find audio feedback easier to understand and more genuine. This supports Lunt and Curran (2009) who found that students are up to ten times more likely to open an audio file than read written feedback. There are perceived benefits to audio feedback in comparison with written feedback, including the ability to provide more detailed and personalised feedback (King, McGugan \& Bunyan, 2008; McCullagh, 2011) through the mode of audio.

More recently, research has started to investigate the use of video as a means of providing individual and personal feedback (Turner \& West, 2013). Crook et al (2012) examined student perspectives of video feedback and found that a significant number of students felt that video feedback increased their understanding of the feedback provided (Thompson \& Lee, 2012). Video feedback provides opportunities for students to listen at their own pace, recap important parts and evaluate their assessed work (Brick \& Holmes, 2008). West and Turner (2016) found that nearly three times as many respondents preferred video feedback in comparison with written feedback. This supports Turner and West (2013) who explored final year undergraduate students' perspectives of feedback. They found that although first year students preferred written feedback, final year students demonstrated a stronger preference for video feedback. Video feedback does not provide dialogic exchanges, but West and Turner (2016) found that students perceived it to represent a dialogue with their lecturer, thus providing insight into how they achieved their grade. Video feedback contains a combination of audio and visual modalities, thus supporting an inclusive approach (Kerr \& McLaughlin, 2008).

Despite the various formats that feedback can come in, how the student interprets and goes on to address the feedback is critical, as is the effect of feedback on their psychological state (Poulos \& Mahony, 2008). Research demonstrates that students prefer feedback that boosts their confidence and selfesteem (Boud, 2007). Feedback which is interpreted to be critical rather than developmental can have a detrimental effect on students' motivation and selfconfidence (Dempsey, Driscoll \& Litchfield, 1993). The impact of feedback on students' self-efficacy is also important (Hattie \& Timperley, 2007) and the less students believe in themselves, the more feedback they require (Knight \& Yorke, 2003). Kluger and DiNisi (1996) found that both positive and negative feedback can be beneficial to learning. However negative feedback can be more powerful (Hattie and Timperley, 2007) than feedback which is too positive (Brunit, Huguet \& Monteil, 2000). Research demonstrates that unclear feedback that fails to clearly specify how students did not meet the assessment criteria can exacerbate negative outcomes and lead to poor future performance (Thompson \& Richardson, 2001). 
Research suggests that feedback is within the top ten influences of learning (Hattie, 2009), and different forms of feedback can influence learning in various ways. It is important that no matter what format feedback is given in, that there are opportunities for feed forward (Morris \& Chikwa, 2016). Overall, research which examines students' perspectives of feedback is limited (Poulos \& Mahony, 2008). Therefore, this study explores students' perspectives of feedback within one higher education institution.

This study explored the following research questions:

- What were participants' perspectives of specific modes of feedback?

- How well did participants engage with feedback to support their academic development?

- How do participants characterise effective feedback?

\section{Method}

Focus groups were used to collect the data in one UK higher education institution. Ethical approval was gained using the institutional process. Seven undergraduate final year students were recruited to participate in the study. All participants were studying a teacher education programme in primary education which led to the award of qualified teacher status. All participants were female and aged 20-25. No males were studying this course. Participants provided informed consent and were assured of their right to anonymity. Two focus groups were conducted, each lasting 20 minutes in duration. The focus groups were recorded and digitally transcribed in line with Jefferson's (1984) transcription conventions. The audio files and transcriptions were stored securely on a password protected electronic cloud. The data were subsequently analysed using thematic analysis by following Braun and Clarke's (2006) steps of thematic analysis. The interview questions are shown in the appendix.

\section{Results}

Following the guidelines of Braun and Clarke (2006), the data were analysed. The analysis led to the development of an overarching theme: 'The use of feedback in higher education', as well as four interpretive themes. A list of the themes and codes are shown in table 1 below.

Table 1: Themes and codes

\begin{tabular}{|l|l|}
\hline \multicolumn{2}{|l|}{ The use of feedback in higher education } \\
\hline Interpretive theme & Descriptive codes \\
\hline Type of feedback & $\begin{array}{l}\text { Verbal feedback } \\
\text { Written feedback }\end{array}$ \\
\hline Principles of feedback & $\begin{array}{l}\text { Components of good feedback } \\
\text { Personal impacts of feedback }\end{array}$ \\
\hline Peer feedback & $\begin{array}{l}\text { Positive considerations } \\
\text { Lecturer knows best } \\
\text { "I think it's a waste of time" }\end{array}$ \\
\hline Future development & $\begin{array}{l}\text { "There's still room for improvement" } \\
\text { Proactive approach } \\
\text { Course external support } \\
\text { Student recommendations }\end{array}$ \\
\hline
\end{tabular}




\section{Type of feedback}

There are now many alternative types of feedback used within higher education, including video and audio modes. However, the participants stated that they had not experienced these modes during their three years of study:

Verbal feedback

Verbal feedback is a widely used approach in higher education. Research suggests that verbal feedback is more personal than written feedback. The participants stated that they generally favoured verbal feedback to written feedback because it was more personal:

"It's more personal as well so you know they've not just written that on everybody's feedback" [Participant 3; Focus Group 1].

For each participant, the work that they produced was 'special' to them as they have invested time and effort into producing an individual piece of work. Consequently, they sought personalised, detailed feedback rather than generic, brief feedback. They expected the lecturer to invest the same degree of effort and time when assessing their work as they had invested in producing it:

"I think well I have worked hard, so why shouldn't they work hard and put in the same effort when marking?" [Participant 4; Focus Group 2].

"I expect the feedback to relate to my work, my ideas, my arguments and my content." [Participant 1; Focus Group 1].

\section{Written feedback}

The participants in the study described disliking written feedback in comparison with verbal feedback:

"Sometimes, when you get written feedback you can read it and completely misunderstand it. Sometimes you get the opposite meaning to that which was intended." [Participant 1; Focus Group 1].

In addition, the students disliked receiving their feedback online:

"I don't like it being online. I never 'get' it" [Participant 4; Focus Group 2].

"It's easier if you can go and collect it and then at least you've got it on paper" [Participant 1; Focus Group 2].

\section{Principles of feedback}

This theme considers aspects that are important for feedback in higher education. It presents the participants' perspectives on 'good' feedback, as well as the personal influences that feedback can have. 
Principles of good feedback

Participants characterised 'good' feedback as providing detailed comments on their work:

"More in depth...not just a small sentence" [Participant 2; Focus Group 2].

"Give an example of how you could do it better" [Participant 3; Focus Group 2].

Participants stated that advice on how they might improve a piece of work was important:

"Some tips for improvement like what we could do to improve" [Participant 1; Focus Group 2].

"It'd be nice to have an opportunity to ask the lecturer questions about the feedback... and say what would you suggest, looking at the feedback? What pointers would you give me in terms of this feedback comment?" [Participant 1; Focus Group 1].

Knowing how to use the feedback to make improvements is a difficult task for many students. However, being provided with feedback that focuses on the mistakes that were made, with no further guidance, will not help students improve their work. Therefore, providing advice and guidelines on how to improve can help students to identify the standard that they are currently achieving, as well as developing their assessment literacy of the standard they need to achieve to gain a higher grade in subsequent assessments. Students can then address the guidance in the feedback to make improvements on future work.

Personal impacts of feedback

This descriptive code examines the impact of feedback on participants. One participant described the beneficial effects of feedback:

"I think it has a positive impact for me because I've used feedback and developed my referencing a lot more" [Participant 3; Focus Group 1].

Some participants explained how their willingness to act on feedback was dependent on how well they had performed in the assessment:

"Although I might get upset, I think I take it [feedback] on board more if

I've got a low grade" [Participant 2; Focus Group 2]. 
"Sometimes it is clear that I have not understood the assessment task and then I get negative feedback and I don't read it" [Participant 2; Focus Group 2].

"Sometimes I get annoyed when I get $68 \%$ because I wanted to get $70 \%$ but I did not know what I needed to do to get over that grade boundary" [Participant 3; Focus Group 1].

Participants described the use of grades as a motivator. They also described how the practice of assigning grades impacted on their sense of self and their resilience:

"No matter how you feel it went you never look at the feedback first, you always look at the grade. If I get a low grade, I feel crushed." [Participant 2; Focus Group 1].

"Once I got $48 \%$ and I thought to myself I'm never going to be able to do any better in this subject." [Participant 1; Focus Group 1].

'If I get a low grade in an assignment, I don't feel like trying next time. It knocks my confidence." [Participant 3; Focus Group 2].

'When I get a high grade, I don't read the feedback. What is the point? I have already got a first." [Participant 3; Focus Group 1].

Some participants indicated that the grade takes a higher priority than the feedback provided. Some suggested that poor performance damaged their confidence, but also identified how high-performance on assessments can also result in lack of engagement with feedback. This can have a detrimental impact on their subsequent academic development.

\section{Peer feedback}

The use of peer feedback is a common strategy within higher education. It provides students with the opportunity to offer constructive comments to their peers by identifying strengths and weaknesses in their work. The participants demonstrated mixed views on peer feedback:

\section{Positive considerations}

Participants discussed how peer feedback can support their academic development:

"I think what's nice is obviously they're in your shoes but they can give you ideas" [Participant 1; Focus Group 1].

"It makes you think, "Well what can I use in my essay that I haven't?"'" [Participant 3; Focus Group 1].

Participants also described the non-threatening nature of peer feedback: 
"It almost takes the pressure off things because you know it's somebody else who's in your position" [Participant 2; Focus Group 1].

Being able to discuss the work with someone who is on the same level removes the barriers that students may feel when they want to discuss feedback with a lecturer. As the students are all completing the same assessment task, they can discuss any issues amongst each other, which can support the development of good team working and social connectivity.

Lecturer knows best

Some participants emphasised the importance of lecturers providing the feedback rather than receiving feedback from their peers:

"They [lecturer] obviously know what they're doing...they've read thousands of assignments so they know what's good and what's not" [Participant 1; Focus Group 2].

"I think it's nice though to do it [peer feedback]. The lecturer can then go through it with us and usually they're kind of clarifying what maybe your peer said" [Participant 1; Focus Group 2].

The lecturer was viewed as an expert within the field and some participants sought lecturer validation before making important changes to their work. Some participants sought validation from someone who they considered to be a reliable source rather than their peers.

"I think it's a waste of time" [Participant 2; Focus Group 2].

"We're peer marking each other's and no one knew whether the other person was right" [Participant 2; Focus Group 2].

"I wouldn't look at it if someone's peer assessed mine because they don't know what they're doing either" [Participant 4; Focus Group 2].

\section{Future academic development}

Participants' described the role of feedback in promoting further academic development.

"There's still room for improvement" [Participant 2; Focus Group 1].

"Even if you get a really good mark there's still room for improvement"

[Participant 3; Focus Group 1].

"I think when you do something wrong it kind of stays in your head and then next time you know not to do it again" [Participant 4; Focus Group 2]. 
"I have got better at it [referencing] and from the feedback I got...so yeah it does help" [Participant 2; Focus Group 2].

These participants recognised how feedback had been useful in shaping their subsequent academic development. However, some also recognised the need to be more proactive by addressing the points for improvement that had been identified by the marker:

"I think it's more of a proactive approach...it's something that you can do and act upon that'll benefit you in the future" [Participant 3; Focus Group 1].

"If you look at your positives you think, oh I did that really well but that bit needs to be improved. You can then use the feedback in your next assignment" [Participant 1; Focus Group 1].

To support future improvements some participants valued the support they could gain from others outside of their course:

"I tend to make appointments with the academic skills advisers and we look through the feedback. I ask, how can I act upon it? so then it's more of a practical approach...It's a completely neutral person who is not a part of our course, which helps" [Participant 3; Focus Group 1].

Participants suggested ways in which their lecturers can support their future academic development:

"It'd be nice to have drop in sessions as well after feedback is provided"

[Participant 1; Focus Group 2].

"For them to actually annotate your assignment... rather than just having a big summary at the end" [Participant 4; Focus Group 2].

\section{Discussion}

This study sought to consider students' perspectives of their feedback within a higher education institution in the UK. Conducting thematic analysis identified four interpretive themes: type of feedback, principles of feedback, peer feedback and future development, with the overarching theme being 'Types of feedback in higher education'. The conclusion taken from the analysis showed that the participants held strong views about feedback, with a mixture of positive and negative perspectives demonstrated.

The findings of this research suggest that students showed a preference for verbal feedback over written feedback. Students perceived verbal feedback to be more personal than written feedback. Participants felt that verbal feedback was more detailed than written feedback. Regardless of the mode of feedback, 
participants indicated a strong preference for feedback which was personal rather than generic and they expressed a preference for detailed feedback. They expected their lecturers to invest the same amount of effort into formulating feedback comments as they had invested in the assignment. They also valued opportunities to discuss their feedback with their lecturer. The perspectives of the participants align with the findings of research by Price, Handley and Millar (2011) who found that students need opportunities to discuss the feedback and ask questions. Some participants stated that receiving a high grade could result in them not using the feedback to support their subsequent academic development. However, if they received a low grade, they were more likely to make greater use their feedback to ensure that they did not repeat their mistakes.

The research also considered the participants' perspectives on peer feedback. In relation to peer feedback their views were mixed. Although peer feedback provided some participants with valuable opportunities to share suggestions for improvement, some preferred to get feedback from their lecturer due to the perceived expertise and experience of the lecturer.

Regardless of the modes of feedback, there are important implications arising from this research. Participants were more likely to not engage with the feedback if they had not understood the assignment task or if it became clear to them that they had not understood the expected standards required to achieve specific grades. This demonstrates the need to develop students' assessment literacy skills prior to asking them to complete an assignment.

It is critical that students understand what the assessment task is asking them to do. Lecturers can facilitate this by providing a verbal briefing in class to outline the requirements of the assessment task. This can then be supplemented with an online video in which the lecturer outlines the requirements of the assignment. Students can then view this in their personal time. The value of using video is that students can replay the video several times, particularly when they are working on the assignment. In addition, the video becomes a permeant resource which students can then access.

There are other ways of ensuring that students fully understand the requirements of a specific assessment task. Providing students with writing frames which outline the specific sections of an assignment can be helpful in the early stages of an undergraduate degree. However, it is important that students do not become dependent upon these and that they do not stifle students' autonomy or creativity. As students progress through their degrees the writing frame should be gradually removed to facilitate student independence and to enable students to demonstrate that they are capable of interpreting an assessment task. In addition, providing students with exemplars of an assessment task is a particularly helpful way of demonstrating to students the requirements of a specific assignment and the expected standard they need to achieve but their use should not foster a dependency culture which restricts independent thinking. 
It is critical that students understand the standards that need to be demonstrated to achieve specific grades. This process should aim to make explicit the standards that students must demonstrate to achieve specific outcomes. Therefore, making explicit the requirements of an assessment task is not sufficient in itself. Students need to have clarity not only on the content of the task but also in relation to the standards that they must demonstrate to achieve particular grades.

Developing students' assessment literacy can be facilitated by 'unpacking' the assessment criteria with them. Assessment criteria in higher education tend to be vague and expressed in unhelpful academic jargon. This means that students are often unable to use the criteria in any meaningful way to achieve the grade that they are aiming to achieve. Lecturers can facilitate this by contextualising generic assessment criteria for specific assignments so that students understand precisely what they need to do in an assignment to achieve a particular standard. Making explicit the standards to students can also be facilitated by sharing exemplars of assignments which represent different standards and asking students to apply the assessment criteria to these to identify the grade which was achieved. If students have the opportunity to actively engage with assessment criteria prior to completing an assignment, they are more likely to utilise the assessment criteria when they work on their own assignment prior to submission.

These suggested pedagogical approaches position students as active agents in the process of assessment and reflect a social constructivist approach to assessment. Assessment in higher education needs to be reconceptualised so that students are active partners in the design of assessment tasks, assessment criteria and the process of applying the assessment criteria to evaluate work. Developing students' assessment literacy skills will enable them to work on their assessment tasks in an informed way rather than working on them blind. Once they fully understand the requirements of the task, the assessment criteria and the expected standards that they are aiming to achieve students have greater assessment literacy and are therefore more likely to achieve a higher standard.

\section{Conclusions}

The study supports existing research on student feedback in higher education. Overall research that considers students' perspectives of feedback is thin and so this study makes a distinct contribution to the field (Poulos \& Mahony, 2008). The study suggests that there is value in lecturers providing students with verbal feedback, although implementing this strategy on courses with large numbers of students in unlikely to be straightforward. In this case course teams should consider providing audio feedback instead of written feedback when marking work electronically. Opportunities for students to discuss feedback with lecturers can support students' academic development by providing them with an opportunity to ask questions and clarify their understanding. Regardless of mode of feedback, it would appear that the students assigned value to 
feedback which is detailed and personalised rather than generic forms of feedback and therefore this has important implications for higher education pedagogy. This study has a small sample size, and therefore the results cannot be generalised beyond its sample. Future research in this area should examine this aspect of pedagogy on a larger scale to aid generalisability of the findings.

\section{References}

Barr, R. B., \& Tagg, J. (1995). From teaching to learning - a new paradigm for undergraduate education. Change, 27, 12-25. https://doi.org/10.1080/00091383.1995.10544672

Bevan, R., Badge, J., \& Cann, A. (2008). Seeing eye-to-eye? Staff and student views on feedback. Bioscience Education, 12(1), 1-15. https://doi.org/10.3108/beej.12.1

Black, P., \& Wiliam, D. (1998). Assessment and classroom learning. Assessment in Education: Principles, Policy and Practice, 5(1), 7-74.

Blair, A. A., \& McGinty, S. (2013). Feedback-dialogues: exploring the student perspective. Assessment \& Evaluation in Higher Education, 38(4), 466-476. https:// doi.org/10.1080/02602938.2011.649244

Boud, D. (2007). Reframing assessment as if learning were important. In D. Boud \& N. Falchikov. (Eds.) Rethinking assessment in higher education: Learning for the longer term. 14-25. London: Routledge.

Boud, D., \& Molloy, E. (2012). Rethinking models of feedback for learning: The challenge of design. Assessment \& Evaluation in Higher Education, 38, 698-712. https://doi.org/10.1080/ 02602938.2012.691462

Braun, V., \& Clarke, V. (2006). Using thematic analysis in psychology. Qualitative Research in Psychology, 14, 77-101. https://doi.org/10.1191/1478088706qp063oa

Brick, B., \& Holmes, J. (2008). Using screen capture software for student feedback: Towards a methodology. Paper presented at the IADIS International Conference on Cognition and Explanatory Learning in Digital Age (CELDA 2008), Freiburg, Germany.

Brunit, S., Huguet, P., \& Monteil, J. M. (2000). Performance feedback and self-focused attention in the classroom: When past and present interact. Social Psychology of Education, 3, 277-293.

Cartney, P. (2010). "Exploring the Use of Peer Assessment as a Vehicle for Closing the Gap Between Feedback Given and Feedback Used." Assessment \& Evaluation in Higher Education, 35(5), 551-564. https:/ / doi.org/10.1080/02602931003632381

Cowan, J. (2010). "Developing the Ability for Making Evaluative Judgements." Teaching in Higher Education, 15(3), 323-334. https:// doi.org/10.1080/13562510903560036

Crook, A., Mauchline, A., Maw, S., Lawson, C., Drinkwater, R., Lundqvist, K., \& Park, J. (2012). The use of video technology for providing feedback to students: Can it enhance the feedback experience for staff and students? Computers $\mathcal{E}$ Education, 58, 386-396. https:// doi.org/10.1016/j.compedu.2011.08.025

Dempsey, V. J., Driscoll, M. P., \& Litchfield, B. C. (1993). “Feedback, retention, discrimination, error and feedback study time.". Journal of Research on Computing in Education, 25(3), 303-326. https://doi.org/10.1080/08886504.1993.10782053

Duncan, N. (2007). Feed-forward: Improving students' use of tutors' comments. Assessment and Evaluation in Higher Education, 32. 271-283. https://doi.org/10.1080/02602930600896498

Evans, C. (2013). Making sense of assessment feedback in higher education. Review of Educational Research, 83, 70-120. https://doi.org/10.3102/0034654312474350 
Falchikov, N. (2005). Improving Assessment through Student Involvement. London: Routledge-Falmer.

Garrison, D. R., \& Anderson, T. (2003). E-Learning in the 21st century: A framework for research and practice. London, UK: Routledge/Falmer.

Gibbs, G., \& Simpson, C. (2004). Conditions under which assessment supports learning. Learning and Teaching in Higher Education, 1(1), 3-31.

Hattie, J., \& Timperley, H. (2007). The power of feedback. Review of Educational Research, 77(1), 81-112. https://doi.org/10.3102/003465430298487

Hattie, J. A. C. (2009). Visible learning: A synthesis of 800+ meta-analyses on achievement. Oxford, UK, Routledge.

Hepplestone, S., \& Chikwa, G. (2014). Understanding how students process and use feedback to support their learning. Practitioner Research in Higher Education, 8(1), 41-53.

Hounsell, D. (1997). "Contrasting Conceptions of Essay-Writing." In The Experience of Learning, edited by F. Marton, D. Hounsell \& N. Entwistle. 106-125. Edinburgh: Scottish Academic Press.

Ivanic, R., Clark, R., \& Rimmershaw, R. (2000). What am I supposed to make of this? The messages conveyed to students by tutors' written comments. In Student writing in higher education. New Contexts, ed. M. R. Lea and B. Stierer. 47-65. Buckingham: Open University Press.

Jefferson, G. (1984). Transcript Potation. In Structures of Social Action: Studies in Conversation Analysis, eds. J Maxwell Atkinson and John Heritage, IX XVI.

Kerr, W., \& McLaughlin, P. (2008). The benefit of screen recorded summaries in feedback for work submitted electronically. In F. Khandia (Ed.), 12th CAA International Computer Assisted Assessment Conference: Proceedings of the Conference, 2008 (pp.153-168). Loughborough: Loughborough University.

King, D., McGugan, S., \& Bunyan, N. (2008). Does it make a difference? Replacing text with audio feedback. Practice and Evidence of scholarship of Teaching and Learning in Higher Education, 3(2), 145-163.

Kluger, A. N., \& DeNisi, A. (1996). The effects of feedback interventions on performance: A historical review, a meta-analysis, and a preliminary feedback intervention theory. Psychological Bulletin, 119(2), 254-284. https:// doi.org/10.1037//00332909.119.2.254.

Knight, P., \& M. Yorke. (2003). Assessment, learning and employability. Maidenhead, UK: SRHE/Open University Press.

Lunt, T., \& Curran, J. (2009). Are you listening please? The advantages of electronic audio feedback compared to written feedback. Assessment Evaluation in Higher Education, 35(7), 759-769. https:// doi.org/10.1080/02602930902977772

MacLellan, E. (2001). "Assessment for Learning: The Differing Perceptions of Tutors and Students." Assessment \& Evaluation in Higher Education, 26(4), 307-318. https://doi.org/10.1080/02602930120063466.

McCullagh, C. (2011). Talking about writing: Exploring the use of audio feedback in EAP writing classes, media-enhanced feedback case studies and methods. In Proceedings of the media-enhanced feedback event. Sheffield, 2010, pp. 2-16. Retrieved from: http://ppp.chester.ac.uk/images/archive/4/43/20110329150 219!Middleton-Media-enhanced_feedback_proceedings-final.pdf

Merry, S., \& Orsmond, P. (2008). Students' attitudes to and usage of academic feedback provided via audio files. Bioscience Education, 11(3), 1-11. https:// doi.org/10.3108/beej.11.3

Morris, C., \& Chikwa, G. (2016). Audio versus written feedback: Exploring learners' preference and the impact of feedback format on students' academic 
performance. Active Learning in Higher Education, 17(2), 125-137.

https://doi.org/10.1177/1469787416637482

Nicol, D. (2010). “From Monologue to Dialogue: Improving Written Feedback in Mass Higher Education." Assessment \& Evaluation in Higher Education, 35(5), 501-517. https:// doi.org/10.1080/02602931003786559

Nicol, D., Thomson, A., \& Breslin, C. (2014). Rethinking feedback practices in higher education: a peer review perspective. Assessment $\&$ Evaluation in Higher Education, 39(1), 102-122. https:// doi.org/10.1080/02602938.2013.795518.

Poulos, A., \& Mahony, M. J. (2008). Effectiveness of feedback: The students' perspective. Assessment \& Evaluation In Higher Education, 33(2), 143-154. https://doi.org/10.1080/02602930601127869

Price, M., Handley, K., \& Millar, J. (2010). Feedback all that effort but what is the effect? Assessment \& Evaluation in Higher Education, 35(3), 277-289. https://doi.org/10.1080/02602930903541007

Price, M., Handley, K., \& Millar, J. (2011). “Feedback: Focusing Attention on Engagement." Studies in Higher Education, 36,(8), 879-896. https://doi.org/10.1080/03075079.2010.483513

Ramsden, P. (2003). Learning to teach in higher education. London: Routledge/Falmer.

Thompson, T., \& Richardson, A. (2001). Self-handicapping status, claimed self-handicaps and reduced practice effort following success and failure feedback. British Journal of Educational Psychology, 71, 151-170. https://doi.org/10.1348/000709901158442

Thompson. R., \& Lee, M. J. (2012). Talking with students through screen casting: Experimentations with video feedback to improve student learning. Journal of Interactive Technology and Pedagogy. Retrieved from: http://jitp.commons.gc.cuny.edu/2012/talking-with-studentsthroughscreencasting-experimentationswith-video-feedback-to-improvestudentlearning/

Turner, W., \& West, J. (2013). Assessment for 'digital first language' speakers: Online video assessment and feedback in higher education. International Journal of Teaching and Learning in Higher Education, 25, 288-296.

Weaver, M. R. (2006). Do students value feedback? Student perceptions of tutors' written responses. Assessment \& Evaluation in Higher Education, 31(3), 379-394. https://doi.org/10.1080/02602930500353061

West, J., \& Turner, W. (2016). Enhancing the assessment experience: Improving student perceptions engagement and understanding using online video feedback. Innovations In Education And Teaching International, 53(4), 400-410. https://doi.org/10.1080/14703297.2014.1003954

Wheatley, L. I., McInch, A. A., Flemind, S. S., \& Lord, R. R. (2015). Feeding back to feed forward: Formative assessment as a platform for effective learning. Kentucky Journal of Higher Education Policy \& Practice, 3(2), 34-63.

Yang, M., \& Carless, D. (2013). The feedback triangle and the enhancement of dialogic feedback processes. Teaching in Higher Education, 18(3), 285-295. 